\title{
Conceptual Design of Small Unmanned Mobile Carrying Marine Floating Body
}

\author{
Yunping Xie, Liangdong Qi , Tao Zhang, Weigang Xie, Yunsiya Zhou
}

\begin{abstract}
Based on the common marine buoy for non dynamic positioning, long-term fixed in a marine environment by way of offshore mooring, monitoring range is greatly reduced and the buoy role has not fully played out. in order to compensate for the limitations of fixed mooring buoy brings, a concept of mobile small carrying marine floating body is presented. This paper starts with the unmanned floating body frame system and the design of floating body is established as a rotary body and the motion response, stability and static water resistance of three typical revolving bodies are compared and analyzed. The optimum rotation parameters are combined with different scale parameters. Moreover, the main equipment parts are selected. The static water resistance and stability of different schemes are further analyzed. Finally, a preliminary scheme for small unmanned mobile carrying marine floating body is innovatively determined.
\end{abstract}

Index Terms - marine floating body; conceptual design; navigation performance; driving force location

\section{INTRODUCTION}

China is a developing maritime power. Marine economic development, marine management, environmental protection, and safeguarding national marine rights and interests are all in urgent need of marine monitoring as a guarantee. In view of the general buoy, the observation can only be carried out at fixed coordinates and the ocean observation data near the coordinate are obtained. If repositioning is needed, it will cost a lot of money and time[1]. Therefore, it is urgent to develop a mobile and unmanned offshore monitoring platform - small carrying floating body. Considering that unmanned movable floating body should have better motion performance, stability and can realize fixed point suspension, this paper establishes a floating body scheme with discus revolving shape, and establishes a floating body scheme which meets the functional and operational requirements through comparative analysis of motion performance and resistance performance. The scheme pioneers the small movable floating body on the sea, and has great practical significance and engineering practical value.

Yunping Xie Professor of Naval Architecture and Ocean Engineering department of Jiangsu University of Science and Technology, China. Research direction: ship overall design and Numerical simulation analysis. $+8613605288539$

Liangdong Qi Postgraduate of Naval Architecture and Ocean Engineering department,Jiangsu University of Science and Technology, China. +8618851408167

Tao Zhang Postgraduate of Naval Architecture and Ocean Engineering department,Jiangsu University of Science and Technology, China.+8615605297890

Weigang Xie Postgraduate of Naval Architecture and Ocean Engineering department,Jiangsu University of Science and Technology, China.+8617368088917

Yunsiya Zhou Postgraduate of Naval Architecture and Ocean Engineering department of Jiangsu University of Science and Technology, China.+8618896658636.

\section{UNMOVABLE FLOATING BODY FRAME}

\section{A. Use of Floating Body and Performance Requirements}

As a small unmanned mobile platform on the sea, the floating body can be used for a temporary channel command, hydrometeorological observation, investigation of lagoon harbor, UAV control relay station, archaeological sunken ship marking, etc. It is a multi-functional carrier form, which can realize small-scale cruise, dynamic positioning and fixed-point hovering functions. The floating body is a ship-borne independent equipment (small-scale self-navigation, need to be hoisted). It can carry unmanned aerial vehicles or related measuring equipment. Below 2 sea level, the speed of no less than $0.4 \mathrm{kn}$ can be achieved and will never be overturned. In addition, the relevant parameters of small floating bodies should meet the requirements shown in Table 1.

Table 1 Main requirements of small floating bodies
\begin{tabular}{|c|c|c|}
\hline Serial number & Main scale & $\begin{array}{c}\text { Parumeter } \\
\text { requirements }\end{array}$ \\
\hline 1 & Deck diameter & $5 \mathrm{~m}$ \\
\hline 2 & Displacement & About $2.5 \mathrm{t}$ \\
\hline 3 & Draft & $\leq 0.9 \mathrm{~m}$ \\
\hline 4 & Depth & $\leq 1.5 \mathrm{~m}$ \\
\hline
\end{tabular}

\section{B. Main Structure of Floating Body}

1) Floating body and accessories

Generally speaking, the main structure of unmanned floating body is composed of floating body, mast, counterweight and bottom support. The mast is the superstructure of floating body, which can carry all kinds of video equipment, radar equipment or relay communication equipment. The design of the bottom bracket is mainly responsible for the placement after the recovery of the mother ship and take into account the role of reducing the center of gravity and improving the stability of the floating body. The position of the support center is arranged for propulsion equipment.

2) Power and power system

Advanced propulsion technology at present mainly includes permanent magnet propulsion motor technology, submarine AIP technology, pod type electric propulsion system, superconducting electromagnetic propulsion technology, etc. Its cost and technology content is high [2]. Small unmanned underwater vehicles and underwater vehicles are usually driven directly by engines such as diesel engines and motors. Diesel engine has the characteristics of large torque and good economic performance, large power coverage, but the weight and volume of the diesel engine is large and it ensures good ventilation requirements. Brushless DC motor is generally used as the driving force, which has good speed regulation and relatively convenient arrangement 
[3-4]. The power supply is usually self contained battery pack and combined with solar panels to extend the charging and discharging time.

3) Control and communication system

There are three main control modes for unmanned floating body on the sea: remote control, autonomous navigation and remote control/autonomous navigation[5]. Remote control is to use remote communication technology to realize information interaction between UAV USV and shore control center to achieve the purpose of remote control of ships. Autonomous navigation control is an intelligent motion control design based on human brain model. It requires the floating body to have a complete dynamic control system, track/course control system, automatic collision avoidance system, fault diagnosis system and emergency handling system[6]. Remote control/autonomous navigation dual-mode is the combination of the first two, but also more common and safe control mode.

\section{ANALYSIS AND DETERMINATION OF THE SHAPE OF FLOATING BODY}

From the analysis of the existing buoys, it is found that the shape of the buoys is mainly two types: rotary and non-rotary, and most of them are rotary. The revolving body is discus shaped, cylindrical, spherical, fish like and derivative. Rotary floating body is generally anchored at sea with excellent anti-overturning performance. It can adapt to various sea conditions under the characteristics of wind, wave and current interference and is widely used. The non rotating buoy is represented by a small ship floating body. The buoy has good wave riding performance.

Compared with non-revolving body, the revolving body will bring unnecessary loss in navigation resistance, but it is very convenient in navigation control. The driving force can move in various directions, and the positioning position can be adjusted in real time to realize dynamic positioning and hovering positioning. At the same time, the revolving body has good stability, so the small floating body choose the revolving body type to realize the function and use requirements of the unmanned floating body.

At present, the SWO6_Wave-scan buoy of FUGRO Company in the Netherlands, Watch-Master buoy of ANSYX Company in Canada and hemispherical 3-METER-DISCUS buoy produced by NDBC Company in the United States have prominent advantages in the retrofitting buoy due to its smaller main body size and years of practice. As shown in Figure 1. There is little difference among the three types of buoys, which mainly results in the difference of the performance of the small-sized floating body concentrated on the wet surface shape of the main floating body. The main parameters of three typical floating bodies are shown in Table 2

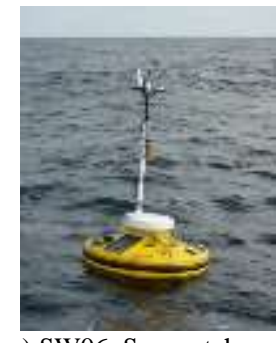

a) SW06_Sea-watch

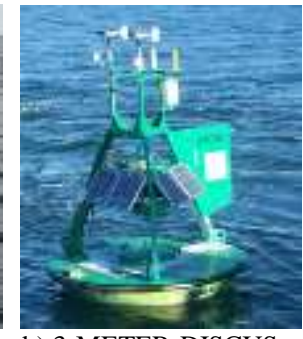

b) 3-METER-DISCUS c) Watch-Master
Fig. 1 Three kinds of excellent buoys
Table 2 Three typical rotary buoys elements

\begin{tabular}{|c|c|c|c|c|}
\hline sctemer & $\begin{array}{c}\text { Funties bery } \\
\text { type }\end{array}$ & Divilacmaxten & Dtunemis & Dantm \\
\hline 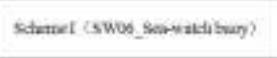 & Deout ber & 2 & $\begin{array}{l}\text { 2S (Botrom } \\
\text { urficet 4) }\end{array}$ & 0.9 \\
\hline 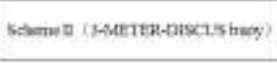 & $\begin{array}{c}\text { Hermiplanicat } \\
\text { tepe }\end{array}$ & 29 & 3 & ats \\
\hline 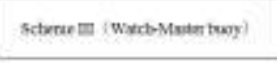 & $\begin{array}{l}\text { Cylatosal } \\
\text { lacr bype }\end{array}$ & 29 & 25 & 09 \\
\hline
\end{tabular}

A. Performance Analysis of Typical Rotating Floating Bodies

\section{1) Motion response}

Because the working environment has a great influence on the floating body, the motion response of the floating body is an important index to measure the performance of the floating body. The rolling and heave directly affect the normal operation of the floating body itself and the equipments on board.

According to the motion response analysis of different wet surfaces of the three schemes, it is concluded that the three cylindrical pitching and rolling motion response of the three schemes is poor, the difference between the two schemes is slight, and the amplitude of the three schemes has little difference [7-8]. The following 2 is the comparison of the amplitude of the three motion.

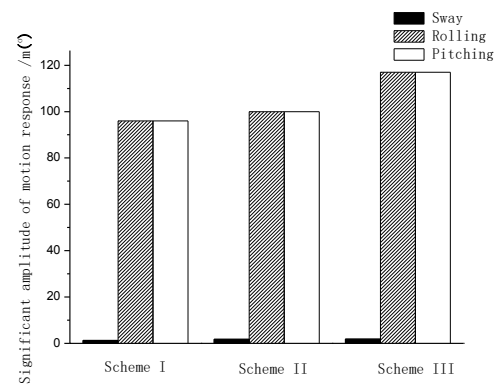

Fig. 2 Amplitude comparison of three schemes

\section{2) Stability}

When floating body works at sea, its stability has higher requirements.For this purpose, a full-scale model of three floating bodies is built in Maxsurf, and the stability curves can be obtained from their weight and center of gravity (Fig. 3). The static stability arm of the three schemes is longer than $0.2 \mathrm{~m}$ at the angle of 30 degrees. The inclination angle of the maximum static stability arm is greater than 30 degrees. All indexes of static stability vanishing angle are greater than 55 degrees, all of them meet the statutory inspection rules of seagoing ships. The initial stabilization height of each scheme is $1.431 \mathrm{~m}, 1.192 \mathrm{~m}$ and $0.736 \mathrm{~m}$, respectively. The first scheme is slightly better than the second and third schemes

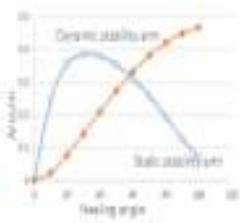

a) Scheme I

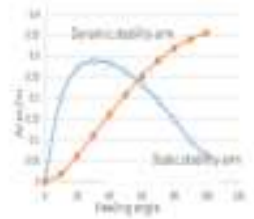

b) Scheme II

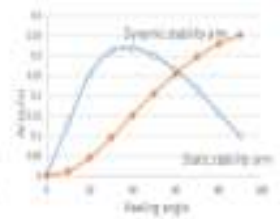

c) Scheme III
Fig. 3 Stability curves of three schemes

\section{3) Resistance to static water}

Similarly, the three schemes are modeled in Solidworks (Fig. 4) and the static water resistance is calculated by numerical simulation software Fine / Marine (Fig. 5). The results show that the static water resistance of scheme I is 542 $\mathrm{N}$, that of scheme II is $493 \mathrm{~N}$, and that of scheme III is $762 \mathrm{~N}$. 


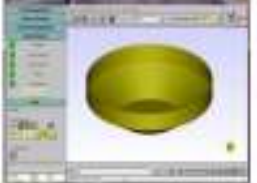

a) Scheme I

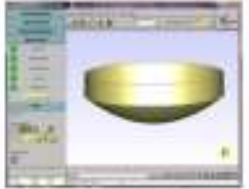

b) Scheme II

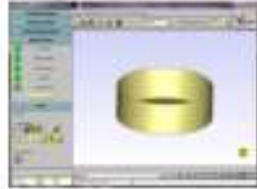

c) Scheme III

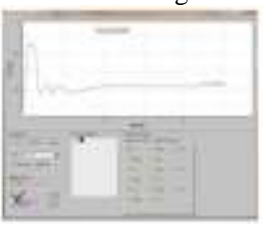

a) Scheme

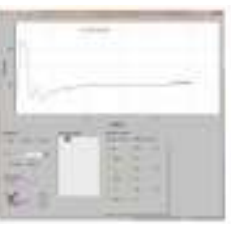

b) Scheme II

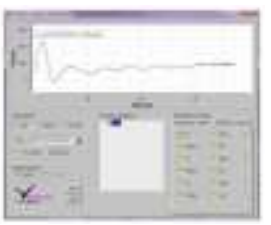

c) Scheme III
Fig. 5 Simulation value of static water resistance

\section{B. Determination of Main Body Shape of Floating Body}

By comparing the motion response, stability and static water resistance of scheme I, scheme II and scheme III, it can be concluded that:1) Scheme I and II are better than scheme III in motion response; 2) Comparison of initial stability of scheme I is slightly better than scheme II and scheme III; 3) The static water resistance of scheme I and scheme II is comparable and obviously smaller than scheme III.

The results show that both schemes I and II meet the design requirements for wet surface shape, but considering the construction process and practical layout, scheme I is most suitable for this small floating body.

\section{OPTIMIZATION OF FLOATING BODY SCHEME}

\section{A. Selection of Main Factors}

According to the determined body shape, its main elements are shown in Figure 6. Considering the need of internal equipment layout and performance assurance, the diameter of discus should not be less than $2.6 \mathrm{~m}$, and its diameter should not exceed $3 \mathrm{~m}$ in combination with its own weight limitation. That is, $2.6 \mathrm{~m} \leq \mathrm{L}_{1} \leq 3 \mathrm{~m}$. When the diameter of the bottom of the discus is too large, the navigation resistance increases obviously. Too small is not convenient for the installation of the propeller and positioning equipment, taking $0.9 \mathrm{~m} \leq \mathrm{L}_{2} \leq 1.5 \mathrm{~m}$. The upper deck diameter is $\mathrm{L}_{3} 1.4 \mathrm{~m}$, considering the layout of the upper structure. In addition, the reference buoys of float depth $H$, height $D_{2}$ and height $D_{1}$ are $1.32 \mathrm{~m}, 0.5 \mathrm{~m}$ and $0.5 \mathrm{~m}$ respectively, while the draught $\mathrm{T}$ varies with the relevant factors and weight.

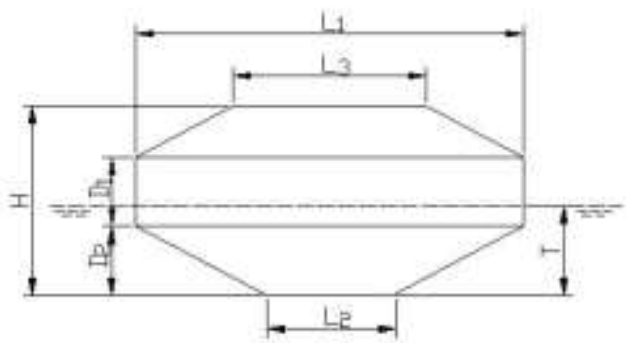

Fig. 6 Schematic diagram of floating elements

\section{B. Programme Establishment And Weight Center of Gravity}

In order to find the main elements combination scheme of the small floating body with excellent performance, the column diameters of the floating body were set at $2.6 \mathrm{~m}, 2.8 \mathrm{~m}$ and $3.0 \mathrm{~m}$, and the bottom diameters were set at $0.9 \mathrm{~m}, 1.2 \mathrm{~m}$ and $1.5 \mathrm{~m}$, respectively. The other elements remained unchanged.
Table 3 Combination of various elements

\begin{tabular}{|c|c|c|c|c|c|c|c|c|c|}
\hline Scheme & 1 & 2 & 3 & 4 & 5 & 6 & 7 & 8 & 9 \\
\hline Diameter of midsle colinn Livin & 3 & 3 & 3 & 2.8 & 2.8 & 2.8 & 26 & 26 & 2.6 \\
\hline Bollom diameter Latm & 09 & 1.2 & 1.5 & 0.9 & 1.2 & 1.5 & 0.9 & 12 & 1.5 \\
\hline
\end{tabular}

Up to now, According to the concept of the scheme determined in reference [9] (Fig. 7), and according to the navigation and dynamic positioning propulsion device, power supply type and capacity, PC104 embedded computer (upper computer) and programmable PLC controller (lower computer) as the main control device are given. The upper computer is responsible for the position reference system and data collection and processing of sensors, as well as path planning and local obstacle avoidance and other autonomous control functions, while the lower computer is responsible for controlling the thrust and rotation angle of the full rotary propeller and water jet pump, so as to achieve free navigation and dynamic positioning (Fig. 8). Combined with the upper frame and the bottom structure, the weight and center of gravity of each combination scheme are preliminarily estimated (Table 4).

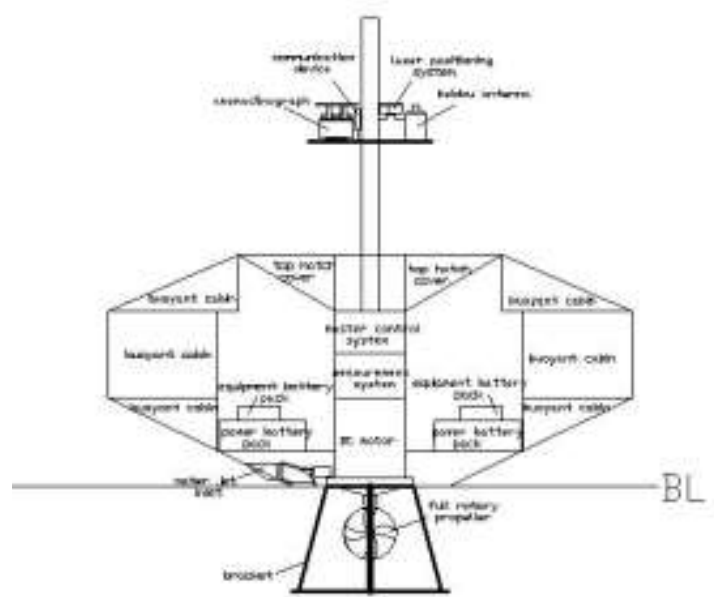

Fig. 7 Schematic diagram of floating body scheme

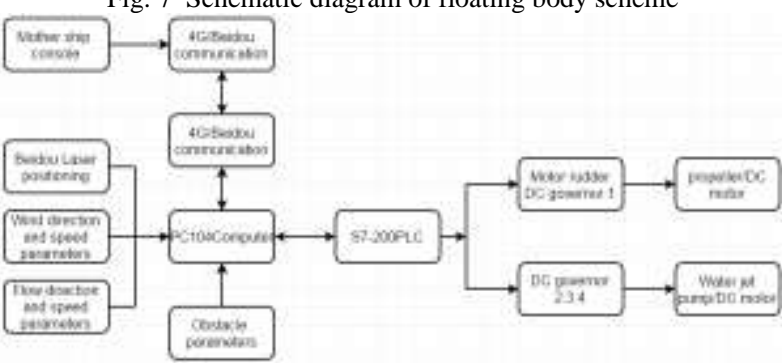

Fig. 8 Integrated block diagram of main control system Table 4 Weight center of each combination scheme

\begin{tabular}{|c|c|c|c|c|c|c|c|c|c|}
\hline Scheme & 1 & 2 & 3 & 4 & 5 & 6 & 7 & 8 & 9 \\
\hline Displacenem $A$ : & 2.465 & 2.008 & 2.528 & 2.438 & 2.458 & 2.478 & 2.406 & 2.427 & 2.450 \\
\hline Orwity Zo'm & 0.400 & $0.40 t$ & 0.392 & 0.409 & 0398 & 0.390 & 0,410 & 0.408 & 039 \\
\hline Dran $T / m$ & 0.617 & 0.503 & 0.592 & 0,650 & 0.630 & 0.6 & 0,716 & 0,645 & $0.64:$ \\
\hline
\end{tabular}

\section{Calculation of Floating Body Scheme}

\section{1) Resistance to static water}

After the actual size of each scheme is modeled, the navigation resistance and positioning resistance of each scheme are also simulated by FINE/Marine. The navigation speed is set at $2.1 \mathrm{~m} / \mathrm{s}(0.4 \mathrm{kn})$ and the flow velocity is set at $0.5 \mathrm{~m} / \mathrm{s}$. The resistance values of the two schemes are calculated as shown in Table 5.

Table 5 Navigation resistance and location resistance

\begin{tabular}{|l|l|l|l|l|l|l|l|l|l|} 
Scheme & 1 & 2 & 3 & 4 & 5 & 6 & 7 & 8 & 9 \\
\hline
\end{tabular}

\begin{tabular}{|l|l|l|l|l|l|l|l|l|l|}
\hline Navigation resistanceN & 415 & 412 & 486 & 500 & 535 & 724 & 808 & 669 & 790 \\
\hline
\end{tabular}

\begin{tabular}{|l|l|l|l|l|l|l|l|l|l|}
\hline Pesitioning rasistancen & 85 & 71 & 96 & 79 & 105 & 117 & 102 & 110 & 120 \\
\hline
\end{tabular} 
According to the resistance data of navigation and positioning conditions, the resistance of scheme 6 , scheme 7 , scheme 8 and scheme 9 is larger, so the stability performance will not be further studied.

\section{2) Stability performance}

Because the function and use of floating bodies require that the floating bodies never overturn, so the vertical coordinate $\mathrm{Z}_{\mathrm{b}}$ of the floating center is greater than the vertical coordinate $\mathrm{Z}_{\mathrm{G}}$ of the center of gravity. According to the underwater part shape of the floating body, combined with the draft of each scheme (Table 4), the vertical coordinates of the floating center can be obtained, as shown in Table 6 .

Table 6 Height of gravity center and height of buoyancy Center

\begin{tabular}{|c|c|c|c|c|c|}
\hline Scheme & 1 & 2 & 3 & 4 & 5 \\
\hline Gravity $/ \mathrm{m}$ & 0.409 & 0.401 & 0.392 & 0.408 & 0.398 \\
\hline Buoyancy Centerim & 0.410 & 0.378 & 0.337 & 0.420 & 0.305 \\
\hline Bucyancy center mimms gravityim & 0.001 & -0.023 & -0.055 & 0.021 & -0.003 \\
\hline
\end{tabular}

It is not difficult to conclude that scheme 2, scheme 3 and scheme 5 do not meet the stability requirements, and scheme 4 has the best stability performance.

\section{Optimization of Floating Body Scheme}

Through the comparison and analysis of the above resistance performance and stability performance, the stability of scheme 4 is better than that of scheme 1 , but its resistance performance is far worse than that of scheme 1 , that is to say, to achieve the same speed, scheme 4 must consume much more energy, thereby increasing the weight of equipment and battery, so the small floating body adopts scheme 1.

\section{CONCUSION}

According to the function and performance requirement of the floating body on the sea, this paper presents a scheme, and analyzes the main body shape of the floating body from the aspects of motion response, initial stability and hydrostatic resistance. Finally, based on the stability and resistance performance, the main factors of the floating body are optimized.The main conclusions are as follows: 1) The shape of discus wet area is adopted for the floating body, and its performance is ideal; 2) The resistance performance and stability of the floating body are related to its shape and size.

Because the small floating body is rare in the sea, there are some limitations in the design and research of floating body, which only play the role of throwing bricks to attract jade.

\section{REFERENE}

[1] Wang Bo, Li Min, Liu Shixuan. Current Situation and Development Trend of Ocean Data Buoy Observation Technology [J]. Instrumentation. 2014, 35 (11): 2401-2414.

[2] Zhang Junxian.Ship electric propulsion and control strategy optimization based on permanent magnet synchronous motor[D].Jimei University, 2015.

[3] Huang Meng. Research on Key Technologies of low power medium speed dual fuel engine [D]. Shandong University, 2016.

[4] Liu Zenglei, Cheng Xiaohua. Development and current situation of Brushless DC motor [J]. explosion-proof motor, 2007 (3): 1-5.

[5] Fraunhofer C M L, Marintek, Chalmers University, et al.Maritime unmanned navigation through intelligence in networks[EB/OL]. https://cordis.europa.eu/project/rcn/104631_en.html. 2012-09-1/2015-8-31.
[6] Wu Gongxing, Zou Jin, Wan Lei, Sun Hanbing. Design of the basic motion control system for water-jet-propelled unmanned surface vehicle[J]. Control Theory \& Applications, 2010, 27(2):257-262.

[7] Sun Chen. Design and Dynamics Analysis of "White Dragon" Buoy [D]. Master's Dissertation of Hangzhou University of Electronic Science and Technology. 2014

[8] Wang Hao. General design and calculation analysis of deep sea buoy [D]. Harbin Engineering University, 2012.

[9] Zhang Tao.Design and Research on Unmanned Small-scale Floating Bodies and Their Hoisting Devices at Sea[D].Jiangsu University of Science and Technology, 2018.

[10] Zhang Baoji. Ship statics [M]. Shanghai: Shanghai Jiao Tong University press, 2016.

[11] Li Jide. Seakeeping of ships [M]. Harbin: Harbin Engineering University press, 2010

Yunping Xie Professor of Naval Architecture and Ocean Engineering department of Jiangsu University of Science and Technology, China Research direction: ship overall design and Numerical simulation analysis. $+8613605288539$

Liangdong Qi Postgraduate of Naval Architecture and Ocean Engineering department,Jiangsu University of Science and Technology, China.+8618851408167

Tao Zhang Postgraduate of Naval Architecture and Ocean Engineering department,Jiangsu University of Science and Technology, China. +8615605297890

Weigang Xie Postgraduate of Naval Architecture and Ocean Engineering department,Jiangsu University of Science and Technology, China.+8617368088917

Yunsiya Zhou Postgraduate of Naval Architecture and Ocean Engineering department of Jiangsu University of Science and Technology, China.+8618896658636. 